\title{
地震時の大規模地下空洞周辺の波動伝播機構 MECHANISM OF WAVE PROPAGATION AROUND LARGE CAVERN DUE TO SV WAVE
}

\author{
大 槻明*・春 海 佳 三 郎** \\ By Akira OHTSUKI and Kasaburo HARUMI
}

\section{1.はじめに}

地震時の岩盤中の空洞周辺応力を理論的に検討した研 究は，いままでに数多くなされている，たとえば, 従来 から用いられてきた方法の 1 つとして, 固有関数で展開 した級数解を使い，円型空洞が無限均一地盤中に存在す る場合の動的解を求めた研究がある1),2).これに対し， 近年では動的境界値問題を積分方程式に帰着させて解く 方法が提案され，任意形状の空洞や多数空洞周辺応力に ついて解析が行われている3).

上述のこれらの研究は, 特に, 定常状態における空洞 表面の最大変位や最大応力といったものがその中心にな っており, 空洞周辺における波動伝播のメカニズムにつ いては触れられていないように思われる. そこで, 本論 文では, 少し視点を変え, 空洞周辺での波動伝播がどの ように行われるか, 特に, 近年空洞の大型化に伴い空洞 の幾何学的寸法に比べ比較的短い波長の地震波が入射し た場合, 空洞がどのような挙動を示すか, 空洞各点の最 大応答值と関連づけて検討した。

\section{2. 解析手法とモデル}

従来から 空洞周辺の 過渡応答解析を行ら方法として は, FEM や差分といった逐次数值解析法がある.FEM は, 複雑な解析を行える反面, データ作成時間や計算時 間, 容量が非常に大きくなる傾向がある. 一方, 差分法 は, 計算時間, 容量が小さい反面, 複雑なモデルを解く ことはできない，そこで，本解析では，すでに開発した 手法4を用い, Fig. 1 に示すように空洞およびその近 傍地盤は FEM で, その他の領城は質点系モデル（一 種の差分) でモデル化する.これにより，上述した手法

* 正会員 清水建設 (株) 大崎研究室

** 理博 群馬大学教授 工学部

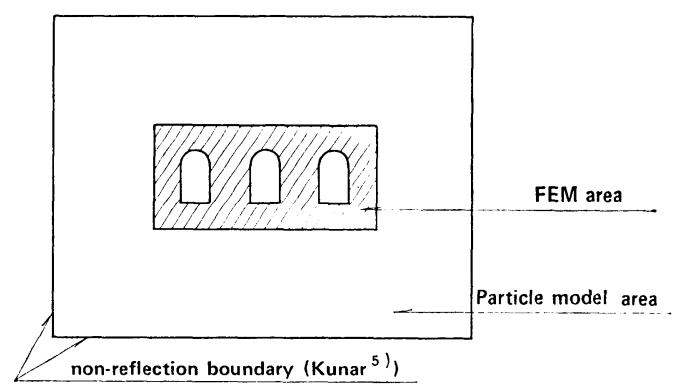

Fig. 1 Analytical model combining FEM with particle model (FDM).

のおのおのの欠点を補 い,より効率的な計算が 可能となった.

本解析に用いる地下空 洞の形状寸法を Fig. 2 に示す. モデル 1 を基本 に, モデル 2 はモデル 1 の空洞が 2 基, モデル 3 は, 空洞が 3 基 $40 \mathrm{~m}$ 間 隔で並列に隣接してい る. 地盤定数は, 縦波速
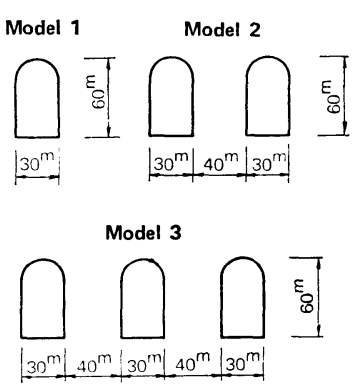

Fig. 2 Analytical model of cavern.
度 $3000 \mathrm{~m} / \mathrm{s}$, 横波速度 $1500 \mathrm{~m} / \mathrm{s}$, 密度 2.6 と仮定し

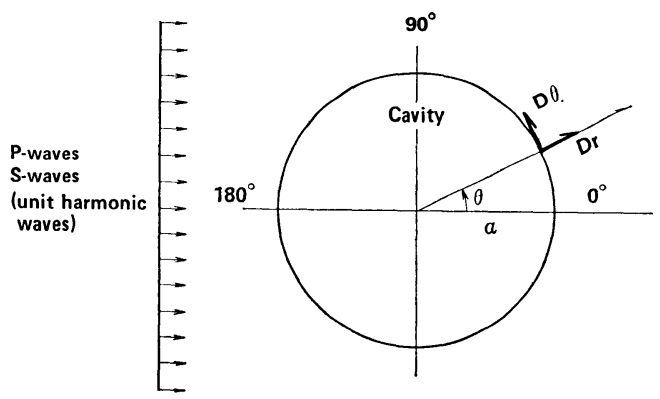

Fig. 3 Analytical model of cylindrical cavity in infinite elastic medium. 
た. 入射波としては, SV 波の Sine 変位波形 を垂直入射する。

\section{3. 解の精度}

Fig. 3 に示した解析モデルについて,まず， 既往の研究結果, $\mathrm{PAO}^{11}$ および $\mathrm{MOW}^{2}$ の解 と比較してみた。

縦波入射の場合空洞表面での最大変位 $D_{r}, D_{\theta}$ を Fig. 4 に示す. 図中には本手法と $\mathrm{PAO}$ の方法によって求めた值をプロットして ある. Fig. 4 をみると $\theta=90^{\circ}$ から $180^{\circ}$ の範 囲では，両手法ともかなりよい一致を示してい る.これに対し $\theta=0^{\circ}$ から $90^{\circ}$ では, 両手法 の結果には若干の差異が認められる。この理由 としては, 本手法による解は波動方程式を直接 数值積分したものであるのに対し，PAO の解 は解析的に求めた定常解であること，また，本 手法では入射波の空洞に沿って回り込む波や空 洞表面の表面波も考虑しているのに対し, $\mathrm{PAO}$ の解では, 空洞よりハンケル関数で逸散する反 射波のみを考慮している違いによるものと思わ れる. 全体的には両手法ともよい一致をみてい る.

\section{横波入射の場合 本手法と $\mathrm{MOW}$ の方法} によって求めた值を Fig. 5 に示す. Fig. 5 をみると，縦波の場合と同様に横波の場合も $\theta$ $=90^{\circ}$ から $180^{\circ}$ では両手法の解は一致してい るが, $\theta=0^{\circ}$ から $90^{\circ}$ では若干の差異が認めら れる.この理由としては，前述したことが同様 に考えられる.

以上のことから，本手法は波長と要素長さ， 伝播速度と時間刻みとの関係を十分に考慮して 計算を行えば，かなりの精度で解が得られるこ とがわかった．精度を保つには以下のことに注 意する必要があろう.要素長さ $(\Delta h)$ は,一波長 (L) を十等分以上分割できる細かさがよい ${ }^{6}$. $\Delta h \leq L / 10$

また，時間刻み $(\Delta t)$ は，次式を満足するよう に決める必要がある.

$$
\Delta t=\alpha \cdot \Delta h / \sqrt{V_{P}^{2}+V_{S}^{2}}
$$

ここで, $V_{P}$ は縦波速度， $V_{S}$ は横波速度である． $\alpha$ は 経験的に 0.8 前後の值をとればよい.

\section{4. 地下空洞周辺の波動伝播機構}

空洞周辺の波動伝播の 模様をみるため, Sine 変位波
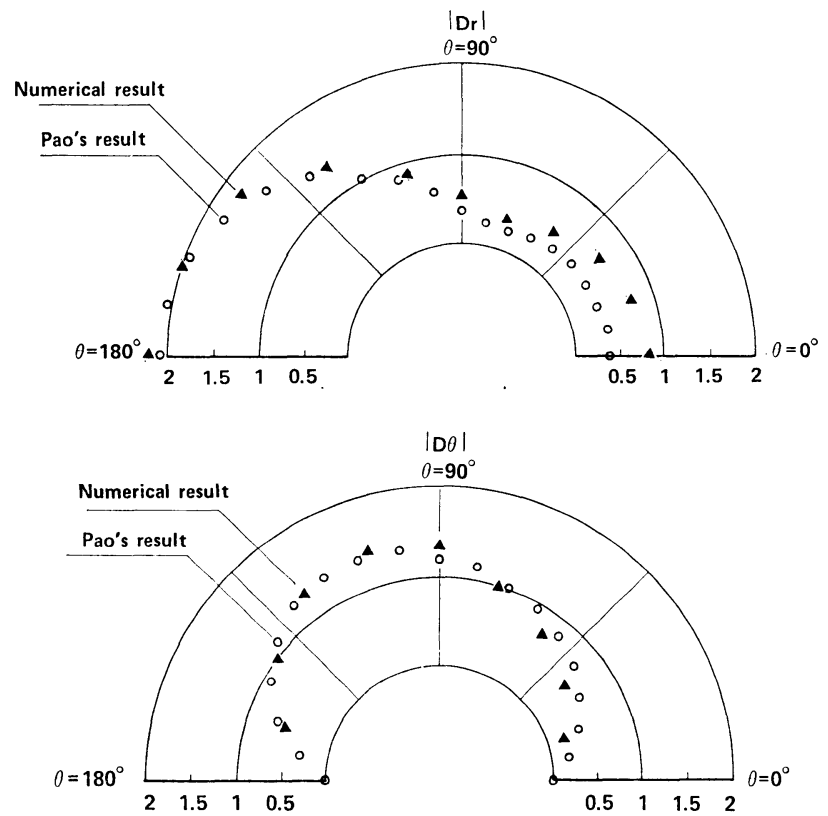

Fig. 4 Distribution of maximum displacement ( $\alpha a=1.57$ incident $\mathrm{P}$ waves).
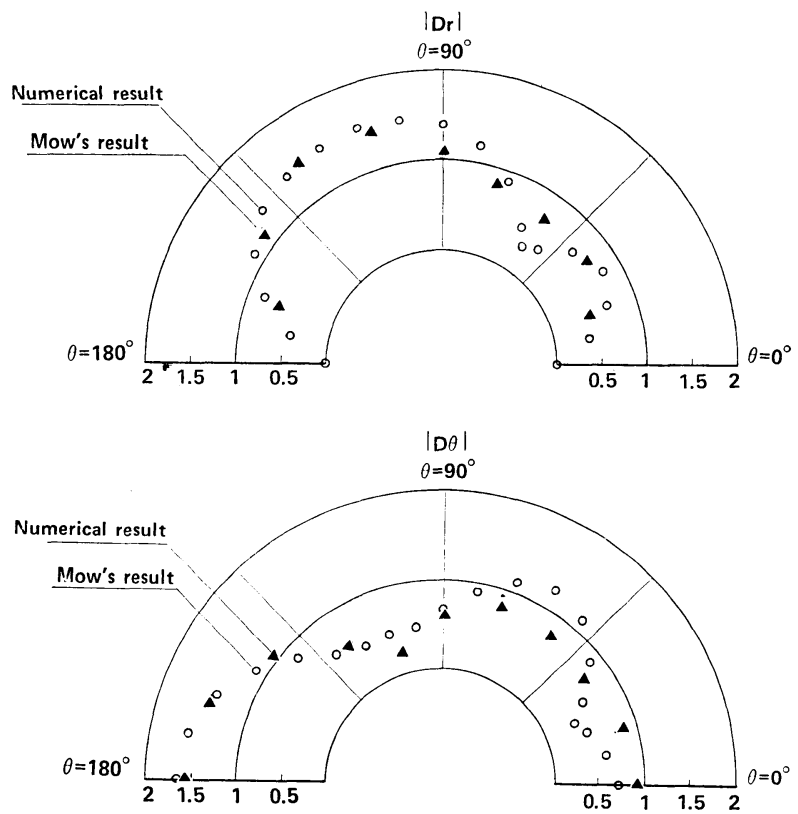

Fig. 5 Distribution of maximum displacement ( $\beta a=1.5$, incident SV waves).

形を 2 波垂直入射させた．Fig. 6 には，ある時刻にお ける空洞およびその近傍の波動伝播状況を変位ベクトル 表示した.ケース 1 では, 空洞寸法に比べて入射波の波 長がかなり長いため $(5 \mathrm{~Hz})$, 空洞が存在することによ る波動の乱れはなく，空洞は周辺地盤の動きと一体とな ってせん断変形している様子が認められる.これに対 


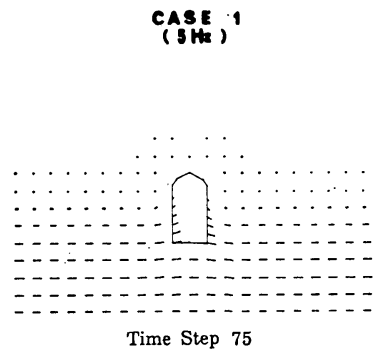

Time Step 75

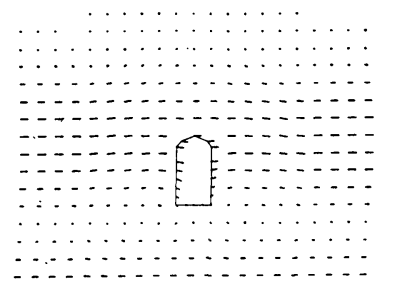

Time Step 100

amplitude of incident wave

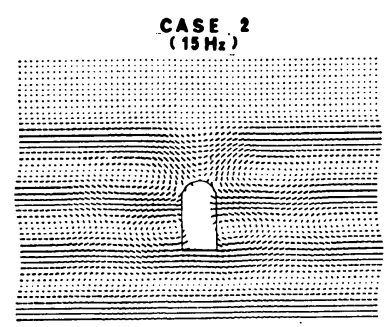

Time Step 75

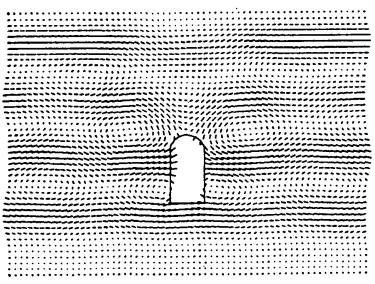

Time Step 100 . amplitude of incident wave

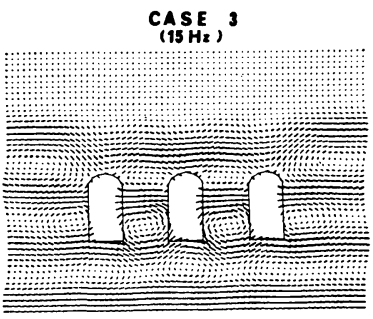

Time Step 75

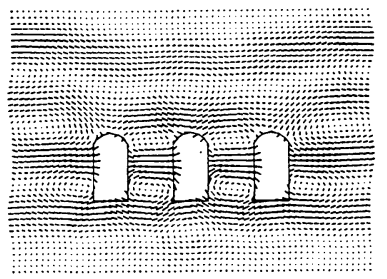

Time Step 100 $\stackrel{u}{\text { amplitude of }}$ incident wave

Fig. 6 Wave propagation around cavern.

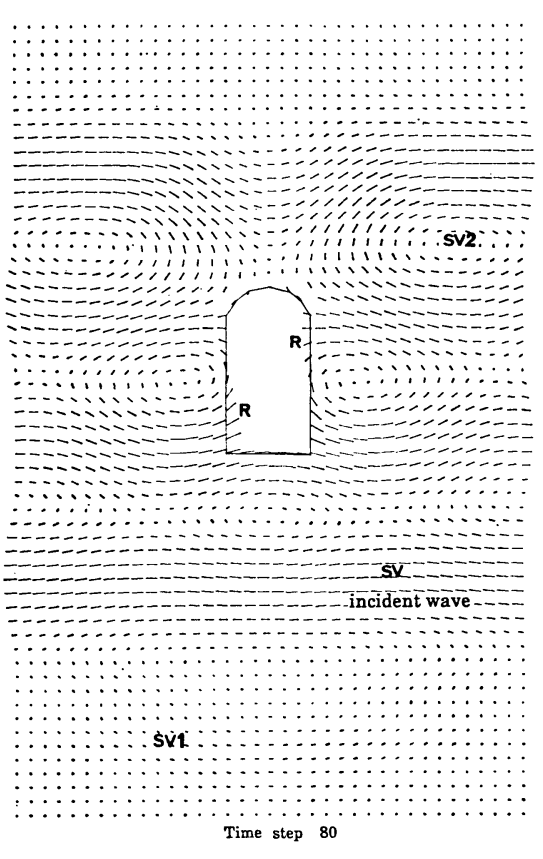

Fig. 7 Wave propagation around cavern (Case 2) due to SV waves of $15 \mathrm{~Hz}$.

し，ケース 2 をみると，入射波の波長がケース 1 の場合 に比べ短くなったため $(15 \mathrm{~Hz})$, 空洞周辺ではかなりの 波動の乱れが認められる.この乱れは Fig. 7 の拡大図 をみるとわかるよらに，おもに，空洞より同心円状に生 じる反射 SV 波 (SV 1) によるもので, この反射 SV 波と入射波 (SV) が合成され 空洞周辺には 渦巻き状の
波（SV 2) が形成されている. 一方，空洞側壁には側壁に沿っ て進む表面波（R）が生じてい る.このため, 側壁には $5 \mathrm{H}_{\mathrm{Z}}$ の場合にみられなかった鉛直動 成分が顕著に認められ，空洞は 複雑な変形モードとなってい る.ケース 3 では, 空洞 3 基の 場合の波動伝播は, ケース 2 の 空洞 1 基の場合のそれと大きく は異なっていない.しかし，中 央の空洞や中央の空洞に面して いる左右の空洞の側壁は隣接す る空洞の影響を若干受けてお り, 振幅が $1 \sim 2$ 割程度 1 基の それよりも大きくなっている.

入射波の波長が空洞寸法に比 べて短くなるにつれ，空洞の挙 動は複雑になっており, 空洞の せん断変形のみを考慮したモデ waves of $15 \mathrm{~Hz}$.

ルだけでは空洞の挙動を十分表現できないことが推測さ れる。

\section{5. 空洞表面の変位分布}

前節の検討 (Fig. 6) から，入射波の周波数 $5 \mathrm{~Hz}$ の 場合よりも $15 \mathrm{~Hz}$ の場合の方が, 空洞およびその周辺地 盤の挙動は複雑であり，また空洞からの反射波も顕著で 


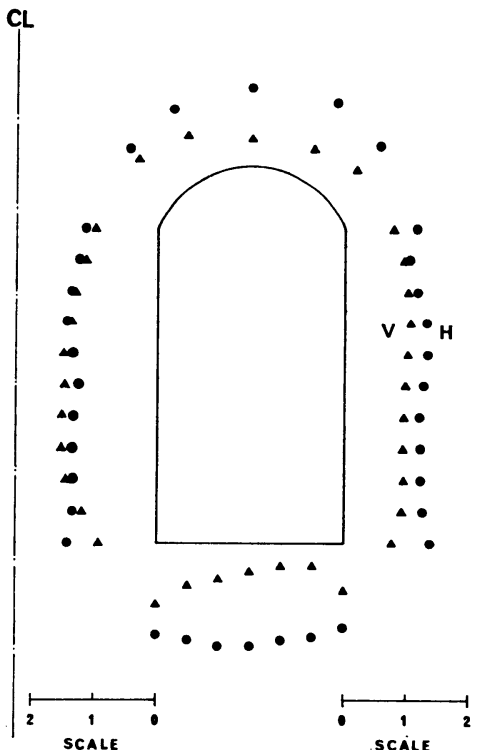

Model 2

Fig. 9 Distribution of maximum displacement due to $\mathrm{SV}$ waves of $15 \mathrm{~Hz}$.

あった. そこで，ここでは，特に $15 \mathrm{~Hz}$ に入射波を限 定し, 定常振動における空洞表平の最大変位を各モデル について調べ, Fig. 8〜10 に示した. 図中, 空洞各点の 最大水平変位を黒丸印で, 最大鉛直変位を黒三角印でプ ロットした. このときの入射波の振幅は単位振幅として 入力した.

空洞 1 基では，空洞底面で水平変位が大きく入射波の 振幅の約 2 倍, 側壁では水平変位のほかに鉛直変位がか なり生じており, 水平変位で 1.5 , 鉛直変位で 1.2 程度 生じている. 一方, 空洞上端部の変位は, 側壁の変位と 同程度のものが生じている. 空洞 2 基では, 空洞が互い に向かい合っている側の側壁で変位の増加がみられ, 水 平変位は 1 基の場合に比べ $1 \sim 2$ 割大きく, 鉛直変位は 1 基に比べ最大 5 割程度大きくなっている. また，その 側壁中央部付近では, 水平変位より鉛直変位の方が大き くなっている. 空洞 3 基の場合は, 2 基の場合と同様に 空洞が互いに向かい合っている側の側壁, 特に中央の空 洞の側壁に, 1 基の場合よりも大きな振幅が認められる. これは，空洞の相互干渉によるものと思われる.

\section{6. まとめ}

入射波の波長が空洞寸法に比べて短くなるにつれ，空 洞の挙動は複雑になるため, 空洞のせん断変形のみを考 慮したモデルだけでは空洞の挙動を十分表現できないこ

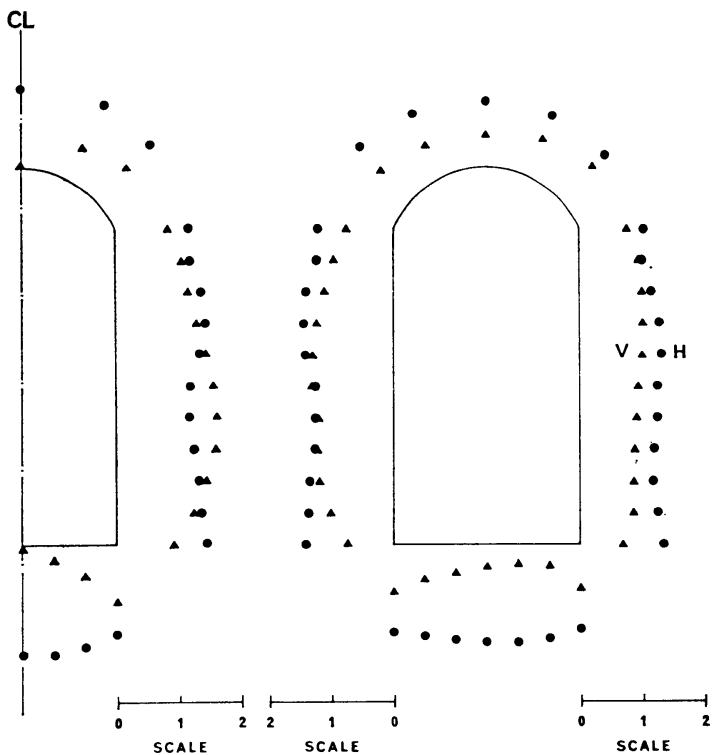

Model 3

Fig. 10 Distribution of maximum displacement due to SV waves of $15 \mathrm{~Hz}$.

とが推測される.すなわち，入射波の波長が短くなると 空洞表面に表面波が生じ, 空洞は鉛直動を含む複雑な変 形モードとなっている. しかし，本手法によって得られ た鉛直動を含む複雑な変形モードをどの程度考慮すれば よいか不明であり, 今後の実測資料の蓄積が必要であろ う. 空洞が隣接することによる影響は, 隣接間隔, 入射 波波長と空洞の比などによって種々異なるものと思わ れる. 本解析結果から空洞が互いに向かい合っている側 の側壁で, 変位が大きくなる傾向が認められた.

\section{参 考 文 献}

1) PAO, Y. : Dynamical stress concentration in an elastic plate, J. Applied Mechanics, pp. 299 305, 1962.

2) Mow, C. and L.T. Ment : Dynamic stresses and displacements around cylindrical discontinuities due to plane harmonic shear waves, J. Applied Mechanics, pp. 598 604, 1973.

3）丹羽義次・小林昭一・横田和男 : 積分方程式による 任意 形状, 多数空洞周辺応力の解析, 土木学会論文報告集, No. 195, pp. $27 \sim 35,1971$.

4) Ohtsuki, A. and K. Harumi : Effect of topographies and subsurface inhomogeneities on seismic SV waves, Earthquake Eng. struct. dyn., Vol. 11, pp. 441 462, 1983.

5) Kunar, W.D. and L. Rodriguez-Ovejero : A model with nonreflectcing boundaries for use in explicit soil-structure interaction analyses, Earthquake eng. struct. dyn., Vol. 8, pp. 361 374, 1980.

6) Ilan, A., L.J. Bond and M. Spirack : Interaction of a compressional impulse with a slot normal to the surface of an elastic half space, geophys, J. 57 , pp. $463 \sim 477,1979$.

(1983.2.8 • 受付) 